\title{
Análisis cuantitativo y cualitativo de las noticias sobre Corea del Sur en los diarios chilenos: El Mercurio, La Tercera, Diario Financiero y Estrategia*
}

\section{Introducción}

$\mathrm{L}$ a imagen de un país es causada por el reconocimiento directo, como la visita al lugar, contacto con los pueblos; y al mismo tiempo por el reconocimiento indirecto, como los medios de comunicación, libros, películas, el arte, etc. Entre ellos, no se puede negar la importancia del papel que desempeñan los medios de comunicación. Según Galtung y Ruse (1965: 64-91), los medios de comunicación poseen el primer lugar en la formación de la imagen de un país.

La prensa cumple un papel de trascendental importancia en la vida política, social y cultural de las naciones. Se ha dicho que el periodismo y la prensa, en consecuencia, son una fuerza social que llega a tener la influencia de un verdadero poder del Estado, constituyendo así lo que ha dado en llamarse el "cuarto poder del Estado". La influencia que ejerce la prensa es tan poderosa y decisiva que es el verda-

* Agradezco el apoyo recibido de la Korea Foundation 2006 para la realización de la presente investigación.

** Profesora auxiliar asociada, Programa de Estudios Asiáticos, Facultad de Historia, Geografía y Ciencia Política, Pontificia Universidad Católica de Chile. dero mentor espiritual de la humanidad.

También, como Valdebenito (1956: 234) señaló, la acción de la prensa contemporánea sobrepasa el estrecho marco de las fronteras y se hace múltiple y cosmopolita. Como la vida de las naciones, el periodismo de nuestros tiempos tiene profundas vinculaciones internacionales. Su mutua interdependencia, en el orden material y espiritual, nace de la necesidad de una más estrecha convivencia humana. Esto sucede porque para su existencia material requiere de materias primas que se producen en el extranjero, y para su existencia espiritual necesita de las noticias de todo lo que ocurre en el universo entero, de manera de satisfacer así las exigencias del lector, ansioso de conocimientos y de ilustración.

En el presente trabajo pretendo establecer ciertas conclusiones a partir de los datos obtenidos mediante el estudio de las noticias que influyeron en la valoración de la imagen de Corea del Sur. Esta investigación tiene el propósito de aportar bases concretas para mejorar el entendimiento mutuo, viendo la percepción que tienen de Corea del Sur y de los coreanos $E l$ Mercurio, La Tercera, Diario Financiero y Estrategia, los diarios más importantes en Chile. 
Como el primer país asiático que firmó un tratado de libre comercio con Chile, y considerando su posición económica en el mundo, Corea del Sur debería tener bastante importancia en el espacio periodístico. Pero al observar las noticias sobre Corea del Sur en la prensa chilena a través de este trabajo, se descubre que algunas podrían transmitir conocimientos inadecuados, y a veces podrían formar imágenes negativas. Según mi juicio, esto es debido a que Corea del Sur es un país recién reconocido en Chile y, al mismo tiempo, a un mal entendimiento por la diferencia cultural entre ambos países.

Por esta razón voy a efectuar un análisis cuantitativo y a la vez cualitativo de las noticias sobre Corea del Sur en los periódicos chilenos ya antes mencionados. Las razones de la selección de los diarios y el periodo de la investigación se explican en el siguiente capítulo. Es preciso mencionar que las observaciones y análisis presentados en este artículo son emitidos desde el punto de vista de una persona surcoreana que no creció en Chile.

\section{Metodología y fase de la investigación}

Como mencionamos anteriormente, los cuatro diarios chilenos que se utilizan en esta investigación son El Mercurio, La Tercera, Diario Financiero y Estrategia.

La primera imprenta fue introducida en España entre los años 1468 y 1474, y desde un principio fue protegida por los reyes católicos Fernando e Isabel. En América, el primer país que tuvo imprenta propia fue México, donde se estableció en el año 1536 (Valdebenito, 1956: 11).

A continuación presentamos una breve historia de la prensa en el mundo hispanohablante. La prensa chilena aparece muy tarde en relación con la de las demás colonias españolas en América. La primera imprenta llegó a Chile en el año 1747, traída por el jesuita Carlos Haimhausen. Quien primero la utilizó fue Camilo Henríquez, el fundador de la prensa chilena, ya que utilizando los tipos de Hoevel comenzó a publicar en 1812 los periódicos $L a$ Aurora de Chile y en seguida El Monitor Araucano.

El siglo XX dio nacimiento en Chile a un periodismo y a una prensa de gran envergadura, hasta entonces ignorados, cuyo carácter es preponderantemente informativo y que son los verdaderos precursores de la prensa chilena y del periodismo contemporáneos (Valdebenito, 1956: 70).

Estos días, las dos cadenas más importantes de la prensa escrita chilena son El Mercurio y Copesa (Consorcio Periodístico de Chile). El Mercurio y La Tercera del Copesa tienen mayor preferencia en Chile por su seriedad. A pesar de su circulación promedio en el país (véase cuadro 1), Las Últimas Noticias, perteneciente al grupo El Mercurio, tiene un contenido más liviano que el diario del mismo nombre. Y está más dirigido hacia los temas de sociedad, la actualidad de la televisión o del mundo del espectáculo, consagrando al mismo tiempo un espacio a temas políticos y económicos; La Cuarta es un diario muy popular cuya fórmula retoma aquella de la prensa británica del espectáculo.

La historia del diario El Mercurio tiene raíces estrictamente comerciales. Se funda el 12 de septiembre de 1827 como El Mercurio de Valparaíso y en su página aparece este lema: "Periódico Mercantil y Político" (Bogart y Giner, 1997: 58). Juan Pablo Illanes, editor de El Mercurio, resume así la historia del diario:

El Mercurio nació moderno. El actual diario fue fundado en 1900 como el primer diario profesional y comercial de Chile que no era portavoz de

MÉXICO YLACUENCADEL PACÍFICO vol. 10, núm. 30 / septiembre - diciembre de 2007 
Cuadro 1

Promedio de circulación neta por día julio-diciembre de 2003

\begin{tabular}{lrrr}
\hline & $\begin{array}{l}\text { Lunes a } \\
\text { viernes }\end{array}$ & $\begin{array}{l}\text { Sábado y } \\
\text { domingo }\end{array}$ & $\begin{array}{l}\text { Promedio } \\
\text { semana }\end{array}$ \\
\hline Diarios generales & & & \\
\hline Matutinos & & & \\
\hline Las Últimas Noticias & 145,205 & 196,579 & 159,883 \\
La Cuarta & 122,966 & 165,053 & 134,991 \\
El Mercurio & 105,113 & 208,238 & 134,577 \\
La Tercera & 91,927 & 200,483 & 122,943 \\
La Nación & 5,157 & 6,053 \\
\hline Vespertinos & & 34,563 \\
\hline La Segunda & 34,563 & \\
\hline Diarios financieros & & \\
\hline Diario Financiero & Sin información & \\
Estrategia & Sin información & \\
\hline Diarios gratuitos & & \\
\hline Matutinos & & \\
\hline La Hora & 100,00 & \\
Publimetro & 87,667 & \\
\hline Vespertinos & & \\
\hline La Hora de la Tarde & 31,000 & \\
\hline
\end{tabular}

Fuente: Mega Time S. A.

nadie. Desde entonces la misión del periódico ha sido siempre estar por encima de las pasiones, templando las luchas con una actitud moderada y conciliadora (Bogart y Giner, 1997: 60).

Actualmente, El Mercurio, propiedad de la familia Edwards, con una dinastía de familias dedicada a la prensa, es considerado como el más importante de los diarios de la prensa chilena.

La Tercera es el segundo gran periódico que aparece diariamente en Chile. Fundado en 1950, es la estrella del grupo Copesa. La Tercera se caracteriza por entregar información importante y por numerosas encuestas sobre la sociedad chilena, especialmente en su suplemento dominical (Embajada de Francia en Chile).

Dos periódicos diarios se reparten el sector de la prensa de información económica. Primero, el Diario Financiero, cercano a los medios de negocios desde algunos años, asociado al Financial Times y al The Economist, de donde retoma una parte del contenido. Su única competencia en el dominio de la información económica es el diario Estrategia, más comprometido políticamente y cercano a la actual oposición. Este último, al igual que el anterior, es un diario económico extremadamente completo, centrado en la actualidad económica y financiera local e internacional (Embajada de Francia en Chile).

Los periódicos que se investigaron en este trabajo son: ${ }^{1}$

- El Mercurio. Año 1950 (la Guerra de Corea, extractos), los meses de septiembre y octubre del año 1988 (los Juegos Olímpicos de Seúl), de noviembre de 1998 a abril de 2006 (desde el comienzo de las conversaciones sobre el Tratado de Libre Comercio entre Corea del Sur y Chile hasta los dos años de vigencia del tratado).

- La Tercera. Año 1950 (la Guerra de Corea, extractos), los meses de septiembre y octubre de 1988 (los Juegos Olímpicos de Seúl), noviembre de 1998-abril de 2006 (desde el comienzo de las conversaciones sobre el Tratado de Libre Comercio entre Corea del Sur y Chile hasta los dos años de vigencia del tratado).

- Diario Financiero. De noviembre de 1998 a abril de 2006 (desde el comienzo de las conversaciones sobre el Tratado de Libre Comercio entre Corea del Sur y Chile hasta los dos años de vigencia del tratado).

- Estrategia. De noviembre de 1998 a abril de 2006 (desde el comienzo de las conversaciones sobre el Tratado de Libre Comercio entre Corea del Sur y Chile hasta los dos años de vigencia del tratado). 


\section{Presentación de datos}

En este capítulo voy a presentar los datos de cada diario. El análisis se divide en dos partes, una de los diarios El Mercurio y La Tercera, y la otra de los diarios de información económica: Diario Financiero y Estrategia. Esta división se debe a que apa- recen noticias parecidas en cada grupo con pocas diferencias entre sí. A mi parecer, es debido a las fuentes de donde consiguen las noticias sobre Corea en particular, es decir, sobre los países extranjeros en general. Los datos incluyen noticias sobre Corea del Norte.

\section{El Mercurio²}

Cuadro 2

El Mercurio: totales por temas y años

\begin{tabular}{lrrrrrrrrrrrr}
\hline & 1988 & 1998 & 1999 & 2000 & 2001 & 2002 & 2003 & 2004 & 2005 & 2006 & Total & $\%$ \\
\hline Corea del Norte & 14 & 4 & 51 & 82 & 26 & 45 & 82 & 15 & 20 & 0 & 339 & 47.81 \\
Economía & 1 & 8 & 21 & 29 & 14 & 30 & 48 & 64 & 18 & 4 & 237 & 33.43 \\
Política & 1 & 0 & 0 & 14 & 2 & 0 & 1 & 2 & 0 & 2 & 22 & 3.10 \\
Sociedad & 2 & 0 & 0 & 0 & 0 & 2 & 0 & 0 & 4 & 1 & 9 & 1.27 \\
RRIl & 2 & 0 & 0 & 0 & 3 & 0 & 0 & 4 & 0 & 2 & 11 & 1.55 \\
Deportes & 10 & 0 & 0 & 0 & 3 & 5 & 0 & 3 & 6 & 0 & 27 & 3.81 \\
Otros & 0 & 0 & 5 & 8 & 1 & 10 & 13 & 15 & 12 & 1 & 65 & 9.17 \\
Total & 30 & 12 & 77 & 133 & 49 & 92 & 144 & 103 & 60 & 10 & 710 & 100.00 \\
\hline
\end{tabular}

Fuente: elaboración propia.

\section{Gráfica 1}

El Mercurio: variables por años, 1999-2005
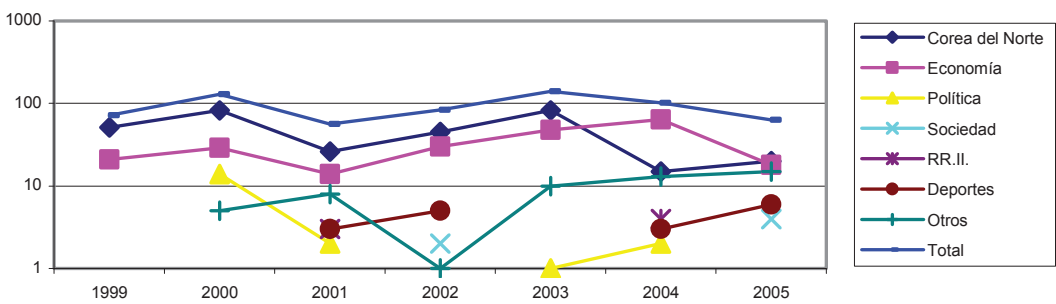

Fuente: elaboración propia.

Gráfica 2

El Mercurio: variables por temas, 1999-2005

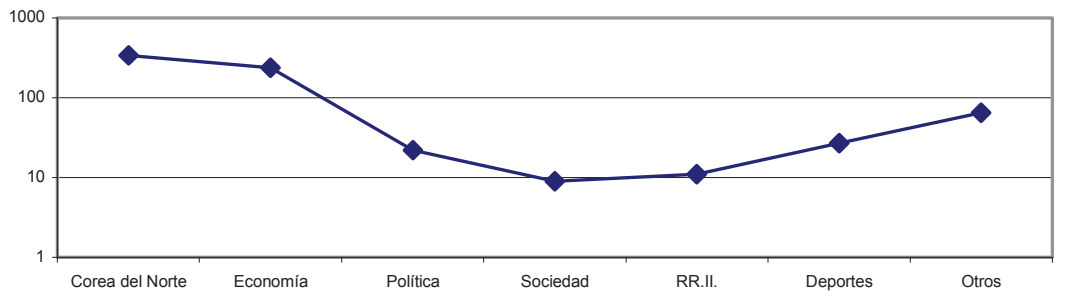

Fuente: elaboración propia. 


\title{
Temas varios del Pacífico
}

\section{La Tercera ${ }^{3}$}

\author{
Cuadro 2
}

La Tercera: totales por temas y años

\begin{tabular}{lrrrrrrrrrrrr}
\hline & 1988 & 1998 & 1999 & 2000 & 2001 & 2002 & 2003 & 2004 & 2005 & 2006 & Total & $\%$ \\
\hline Corea del Norte & 0 & 0 & 0 & 5 & 0 & 12 & 95 & 51 & 119 & 2 & 284 & 33.85 \\
Economía & 5 & 4 & 5 & 2 & 2 & 34 & 43 & 53 & 25 & 3 & 176 & 20.98 \\
Política & 0 & 0 & 0 & 0 & 0 & 0 & 1 & 4 & 0 & 0 & 5 & 0.60 \\
Sociedad & 0 & 0 & 0 & 0 & 0 & 1 & 4 & 2 & 14 & 4 & 25 & 2.98 \\
RRIl & 9 & 0 & 0 & 0 & 2 & 1 & 11 & 38 & 32 & 0 & 93 & 11.08 \\
Deportes & 33 & 7 & 2 & 2 & 5 & 114 & 3 & 13 & 24 & 10 & 213 & 25.39 \\
Otros & 0 & 0 & 0 & 3 & 1 & 1 & 4 & 11 & 18 & 5 & 43 & 5.13 \\
Total & 47 & 11 & 7 & 12 & 10 & 163 & 161 & 172 & 232 & 24 & 839 & 100.00 \\
\hline
\end{tabular}

Fuente: elaboración propia.

\section{Gráfica 3}

La Tercera: variables por años, 1999-2005

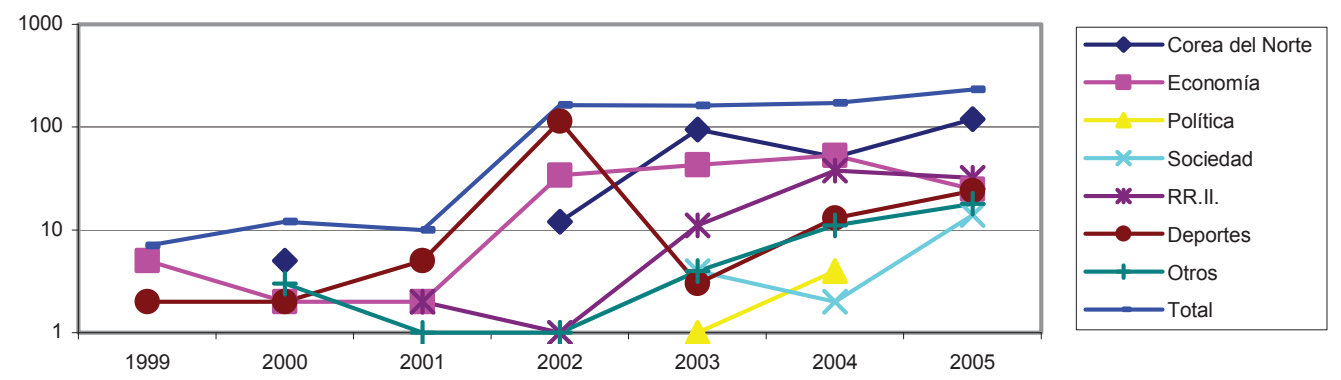

Fuente: elaboración propia.

\section{Gráfica 4}

La Tercera: variables por temas, 1999-2005

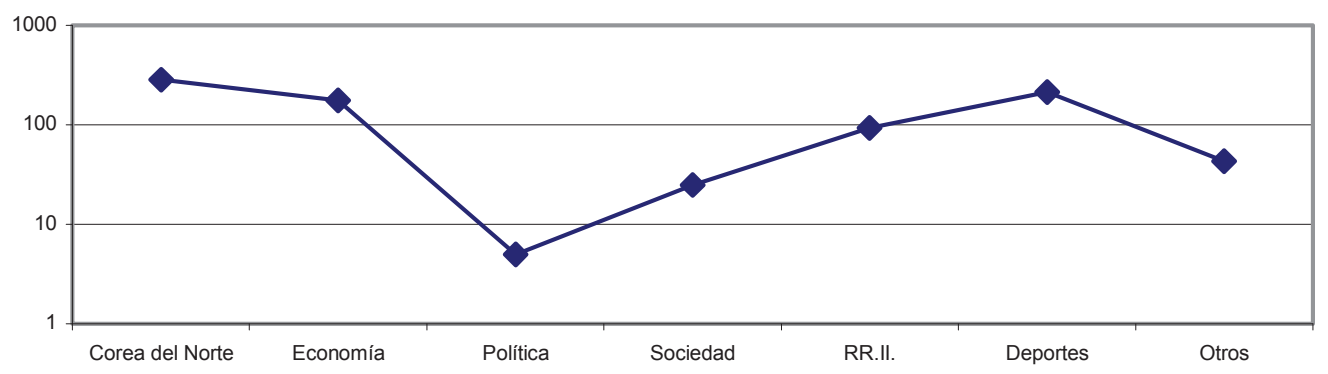

Fuente: elaboración propia. 


\section{Diario Financiero}

\section{Cuadro 3}

Diario Financiero: totales por temas y años

\begin{tabular}{lrrrrrrrrrrr}
\hline & 1998 & 1999 & 2000 & 2001 & 2002 & 2003 & 2004 & 2005 & 2006 & Total & $\%$ \\
\hline Economía & 11 & 57 & 15 & 4 & 67 & 32 & 112 & 14 & 21 & 333 & 90.98 \\
Corea del Norte & 0 & 0 & 1 & 0 & 1 & 1 & 4 & 7 & 2 & 16 & 4.37 \\
Política & 0 & 0 & 0 & 0 & 0 & 2 & 4 & 1 & 1 & 8 & 2.19 \\
Sociedad & 0 & 0 & 0 & 0 & 0 & 0 & 0 & 0 & 1 & 1 & 0.27 \\
RRII & 0 & 0 & 0 & 0 & 0 & 0 & 0 & 6 & 0 & 6 & 1.64 \\
Otros & 0 & 0 & 0 & 0 & 0 & 0 & 0 & 2 & 0 & 2 & 0.00 \\
Total & 11 & 57 & 16 & 4 & 68 & 35 & 120 & 30 & 25 & 366 & 100.00 \\
\hline
\end{tabular}

Fuente: elaboración propia.

\section{Gráfica 5}

Diario Financiero: variables por años, 1999-2005

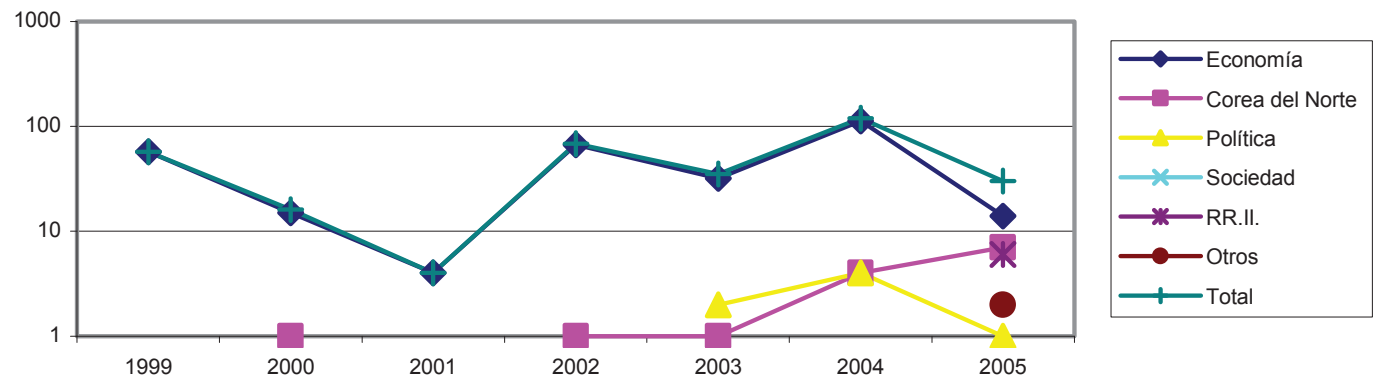

Fuente: elaboración propia.

\section{Gráfica 6}

Diario Financiero: variables por temas, 1999-2005

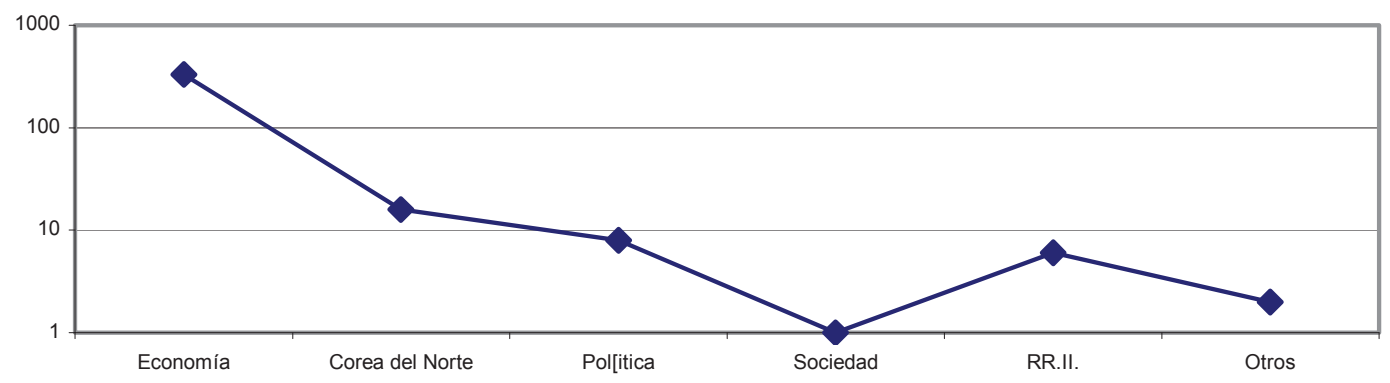

Fuente: elaboración propia. 


\section{Temas varios del Pacífico}

\section{Estrategia}

\section{Cuadro 4}

Estrategia: totales por temas y años

\begin{tabular}{lrrrrrrrrrrr}
\hline & 1998 & 1999 & 2000 & 2001 & 2002 & 2003 & 2004 & 2005 & 2006 & Total & $\%$ \\
\hline Economía & 31 & 303 & 229 & 158 & 219 & 229 & 355 & 255 & 86 & 1865 & 96.48 \\
Corea del Norte & 0 & 0 & 1 & 2 & 6 & 11 & 1 & 3 & 0 & 24 & 1.24 \\
Política & 0 & 0 & 0 & 1 & 2 & 2 & 0 & 0 & 1 & 6 & 0.31 \\
Sociedad & 0 & 0 & 0 & 1 & 2 & 3 & 5 & 1 & 0 & 12 & 0.62 \\
RRII & 1 & 0 & 2 & 1 & 0 & 1 & 0 & 1 & 0 & 6 & 0.31 \\
Otros & 0 & 0 & 0 & 0 & 6 & 2 & 10 & 1 & 1 & 20 & 1.03 \\
Total & 32 & 303 & 232 & 163 & 235 & 248 & 371 & 261 & 88 & 1933 & 100.00 \\
\hline
\end{tabular}

Fuente: elaboración propia.

Gráfica 7

Estrategia: variables por años, 1999-2005

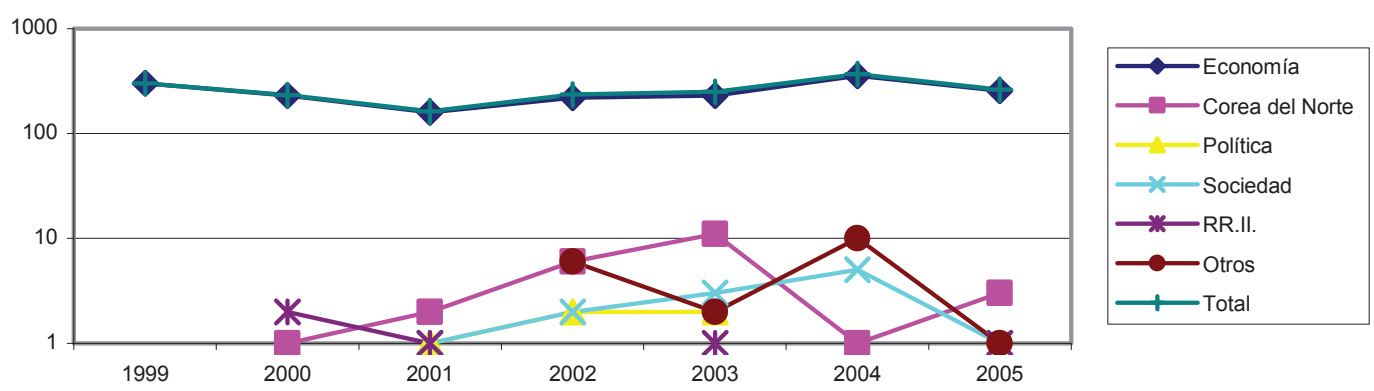

Fuente: elaboración propia.

\section{Gráfica 8}

Estrategia: variables por temas, 1999-2005

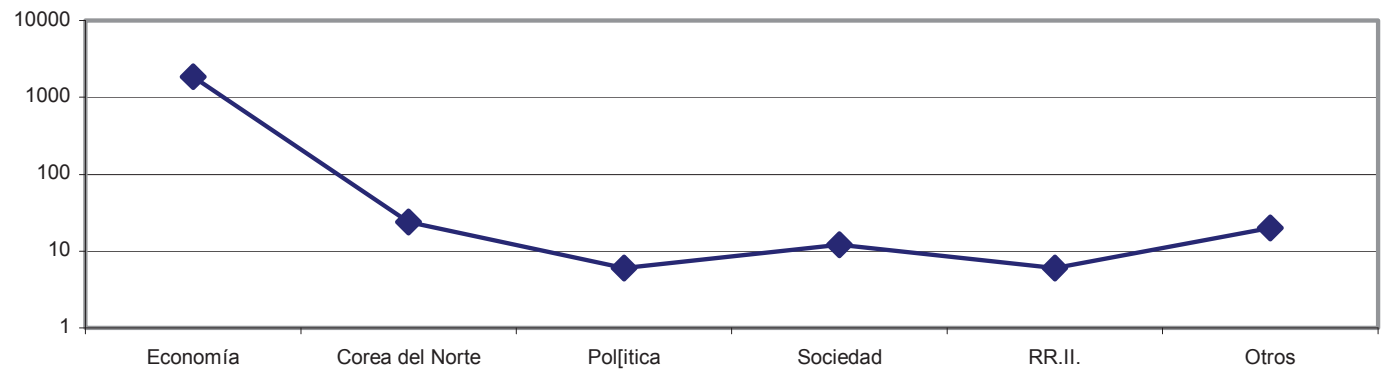

Fuente: elaboración propia. 


\section{Análisis}

\section{Comentarios de El Mercurio y La Tercera}

Ya hemos mencionado anteriormente las dos cadenas más importantes de la prensa escrita chilena: El Mercurio y el Consorcio Periodístico de Chile, que posee La Tercera.

Como se observa en los cuadros 1 y 2 , ambos periódicos dan mayor importancia a los temas de Corea del Norte, o problemas entre ambas Coreas y a la economía de Corea del Sur. El porcentaje de los demás es lo mismo pero La Tercera ocupa más espacio en la sección de "Relaciones internacionales" y de deporte que El Mercurio.

En el año 2000 destaca el hecho de que hay más noticias en El Mercurio que en La Tercera; aquél puso mayor atención a Corea del Norte en el ámbito internacional. Y la notable cantidad de las noticias en La Tercera sobre las golfistas coreanas, ganadoras en los concursos internacionales con significativo número de noticias sobre Corea del Norte.

Sin duda los Juegos Olímpicos de Seúl fueron el gran motor de las informaciones sobre Corea del Sur. Sin embargo, una serie de continua entrega de informaciones negativas apareció a lo largo de los juegos en ambos diarios. Destacaron los disturbios estudiantiles, las quejas en cuanto a ciertos aspectos de la organización y el bochornoso caso del boxeador coreano que provocó serios incidentes que involucraron al público que lo apoyó. En estos casos, la violencia fue una característica de los acontecimientos. Los logros deportivos por parte de los coreanos casi no fueron mencionados por los periódicos.

Las noticias sobre Corea aumentaron desde el año 1999 con las conversaciones acerca del TLC entre Corea del Sur y Chi- le. Además, ambos diarios muestran su continuo interés por los asuntos de Corea del Norte. Es sumamente significativo apreciar que las noticias negativas como los problemas de Hyundai, la corrupción, violencia extrema o proteccionismo económico sobre Corea del Sur aparecidas en los diarios económicos (Diario Financiero y Estrategia) casi no son mencionadas en los diarios El Mercurio y La Tercera.

Es importante destacar que las informaciones sobre Corea del Sur son escasas o no se presentan en áreas visibles para un lector promedio del diario, es decir, para poder delinear una "imagen" coreana es necesaria una exhaustiva y periódica lectura del diario, ya que existen informaciones sobre Corea del Sur que están presentes en secciones que están dirigidas a públicos específicos y que pueden no ser de interés para el común de los lectores.

\section{Comentarios de Diario Financiero y Estrategia}

El Diario Financiero y Estrategia son publicaciones del ámbito económico que intentan dar a conocer la información más relevante del mundo empresarial y financiero, tanto nacional como internacionalmente.

En El Mercurio y La Tercera Corea del Norte es un tema principal de estos diarios económicos pero no superan su interés por la economía. El Diario Financiero dedica más espacio a los autos y Estrategia al mercado de acciones con detalles.

En 2004 se firmó el TLC entre Corea del Sur y Chile. Lo que podría haberse convertido en un dato estadístico significativo respecto a la información sobre Corea del Sur no tuvo el impacto que se esperaba. Es cierto que paulatinamente la información sobre Corea aumentó desde el año 2002 
hasta 2004, pero estas noticias bajaron a partir de febrero de 2004.

Luego de la firma del TLC, Corea del Sur dejó de ser novedad y volvió a descender en términos de notoriedad periodística. Esta conclusión se reafirma en la importancia que se le dio a Corea del Sur en 1999 y que se produjo debido a las causas estacionales mencionadas anteriormente.

Un ejemplo claro de esta situación se observa en las noticias específicas sobre Corea del Sur. La información sobre "sociedad" y "otros" creció hacia 2004; los temas deportivos lo hicieron en 2002 (Copa Mundial Corea-Japón 2002) y las noticias norcoreanas en 2003 (mayor año de tensión con Estados Unidos). Todas estas categorías casi desaparecieron al terminar el evento particular que les permitió su mayor divulgación.

Antes de la firma del tratado se informó sobre el beneficio de este pacto comercial y luego de su firma se publicó continuamente sobre el incremento de las relaciones comerciales y de los productos que se intercambiaban. Sin embargo, las noticias relacionadas específicamente con este pacto comercial disminuyeron paulatinamente.

La firma del TLC no modificó la cantidad de noticias sobre Corea del Sur de manera que este país se posicionara en la pauta periodística. Tampoco se logró posicionar otros temas sobre Corea del Sur (por ejemplo, "sociedad" y "otros"), ya que éstos casi desaparecieron tras la firma.

Resulta interesante observar cómo las notas referentes a Corea del Sur se mueven sobre dos polos. Por un lado tenemos el desarrollo económico, representado especialmente por las empresas surcoreanas de diversa índole (Diario Financiero), y las automotrices (Estrategia), gigantes empresariales exitosos que irrumpen en los mercados mundiales; por otra parte, encontramos serias visiones negativas acerca de Corea del Sur que se relacionan con la sobreprotección económica, los problemas internos, la crisis nuclear con Corea del Norte y los actos ilegales de algunas empresas surcoreanas.

Lo que sí se logró fue posicionar positivamente a Corea del Sur en el imaginario de los lectores del diario, ya que casi todas las noticias sobre el TLC se referían positivamente sobre este país.

\section{Conclusión}

Una vez formada una imagen, las personas interpretan y juzgan las cosas según esa imagen más que según la información o conocimiento objetivos. Por lo tanto, la imagen reconocida reemplaza al aspecto real y tiene fuerte influencia en la reacción de los individuos. Además, la imagen de un país se forma cuando se tienen diversos conocimientos sobre los atributos de la política, sociedad y cultura que componen un país.

La imagen de un país que se transmite a través de los medios de comunicación no puede reflejar la situación real, esto en el sentido de que hay muchas posibilidades de exagerar, reducir, torcer o embellecer la realidad según sus características. Sin 
embargo, los medios de comunicación influyen en la opinión y la actitud del pueblo por medio del contacto y acercamiento a ellos.

Este estudio muestra que las noticias sobre Corea del Sur en los diarios chilenos no varían y se informa alrededor de los acontecimientos y casos. Eso significa que éstas no están en un nivel como para que una persona pueda formarse una imagen sobre Corea del Sur cuantitativa o cualitativamente. Antes y después de la firma del Tratado de Libre Comercio crecieron las noticias sobre un cierto nivel durante un momento, pero empezaron a disminuir desde el año 2005.

En los casos de El Mercurio y La Tercera, los principales intereses sobre Corea son el tema de Corea del Norte, lo cual puede afectar negativamente en la formación de la imagen de Corea del Sur. También las protestas de los campesinos y de los universitarios aparecen en varias ocasiones.

En Diario Financiero y Estrategia las noticias distintas de las económicas y las de la sociedad aparecieron en el momento de la firma del Tratado de Libre Comercio, pero pronto desaparecieron.

La construcción de la imagen positiva de un país tiene influencia directa o indirectamente en la fuerza competitiva de un país. La imagen positiva de un país constituye un rol importante para mantener y desarrollar las relaciones diplomáticas, comerciales y turísticas.

Para quienes no es fácil experimentar Corea del Sur, es necesario ofrecer una imagen positiva a través de los medios de comunicación. En este sentido, es indispensable ofrecer la información adecuada y una traducción correcta. miv

\section{Notas}

1. Los datos de los periodos desde enero hasta abril de 2006 de Diario Financiero, desde noviembre de 1998 a abril de 2006 de Estrategia, desde 1950 hasta 1953, 1988, y de enero a abril de 2006 de La Tercera fueron recoleccionados por César Lara, asistente de los meses de abril a agosto de 2006.

2. Sobre la Guerra de Corea, que duró tres años desde 1950 a 1953 , hubo 17 noticias en el año 1950 en este diario. Sin embargo, no se pudo lograr encontrar más noticias porque los materiales están sumamente deteriorados y es imposible establecer con ellos un trabajo metodológico.

3. Sobre la Guerra de Corea, los números disponibles desde los meses de julio a diciembre del año 1950, del año 1951 y del año 1952 hubo 232 noticias. En general, se muestra una recopilación del material internacional sobre la guerra. Se mantiene la utilización de términos referidos a Corea o a la guerra para ejemplificar ciertas situaciones de la actualidad noticiosa chilena. Durante el periodo de estudio los principales ejes noticiosos fueron: los intentos de paz, los problemas con los prisioneros de guerra y los problemas políticos al interior de Corea del Sur. Cabe destacar que es interesante que aparezcan diversas noticias donde se expresa claramente el protagonismo de ciudadanos surcoreanos. Pero resultó negativa la utilización de términos coreanos para ejemplificar contextos específicos. Por ejemplo, la nota sobre un barrio "coreano" relaciona a Corea con conceptos como la "pobreza" y el "abandono". También se mantiene presente la idea de conflicto y la utilización de conceptos relacionados con la guerra. Aparece el polémico gobierno del presidente Rhee y las violentas manifestaciones que llevaron a cabo estas informaciones con las noticias en ese momento sobre protestas en Corea y los problemas de corrupción de la clase política y empresarial coreana. Pero, a pesar de las noticias negativas sobre actores surcoreanos, el periódico destaca en dos ocasiones la valentía y el "coraje" de las fuerzas surcoreanas y la "nobleza" de los pobladores afines a la causa de Corea del Sur.

MÉXICO YLACUENCADEL PACÍFICO vol. 10, núm. 30 / septiembre-diciembre de 2007 


\section{Temas varios del Pacífico}

\section{Bibliografía}

Bogart, Leo, y Juan Antonio Giner (1997) Éxitos y desafíos, la situación de la industria periodística latinoamericana: 32 perfiles de diarios, informe presentado con ocasión del Encuentro Mundial de Entidades Periodísticas en Porto Alegre, Brasil, 5 y 6 de febrero.

Galtung, Johan, y Mari Holmboe Ruge (1965) "The Structure of Foreign News", Journal of Peace Research, vol. 2, pp. 64-91.

Valdebenito, Alfonso (1956) Historia del periodismo chileno 1812-1955, $2^{a}$ edición. Santiago, Chile: Universidad Católica.

\section{Bibliografía electrónica}

Corrales, J., y M. Sandoval (2005) Concentración del mercado de los medios, pluralismo y libertad de expresión, Centro de Estudios de la Comunicación, Instituto de la Comunicación e Imagen, Universidad de Chile. http://www.comunicacion.uchile.cl/ docs/corrales2005.pdf

Embajada de Francia en Chile (s/f) Los medios en Chile. http://www.france.cl/espanol/article. php3?id_article $=410$ 